\title{
استراتيجيات التعليم الرقمي في المدراسة الجزائرية
}

\author{
اعتصات

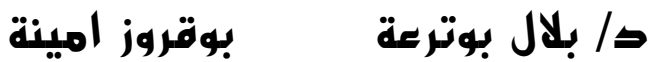 \\ جامعة حمده لخضر - الوادي- الجز ائر

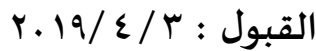 \\ r.19/1/YN : الاستلام
}

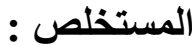

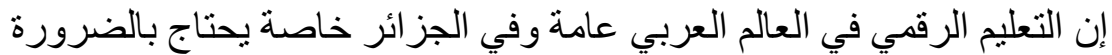

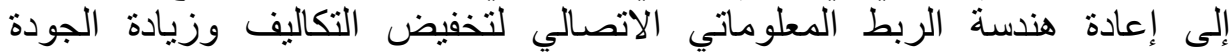

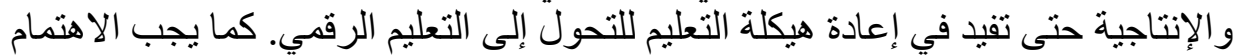

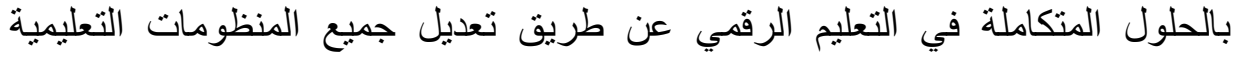

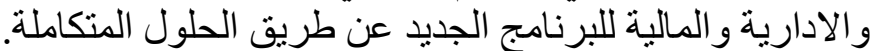

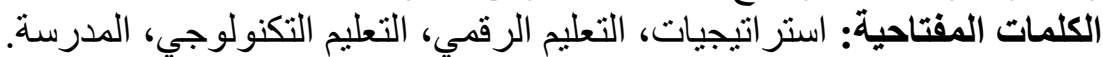

\section{Abstract:}

Digital education in the Arab world in general and in Algeria in particular needs to re-engineer communication connectivity to reduce costs and increase quality and productivity to benefit in the restructuring of education to transform into digital education. Attention should also be given to integrated solutions in digital education by modifying all educational, administrative and financial systems for the new program through integrated solutions.

Keywords: strategies, digital education, technological education, school.

شهر العالم العربي في العشر سنوات الأخيرة تقدما هائلا في تكنولوجيا

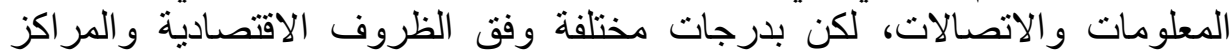

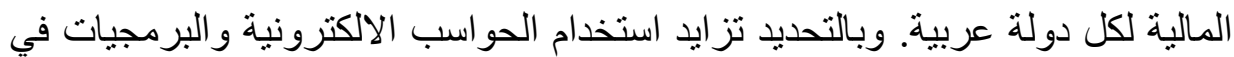

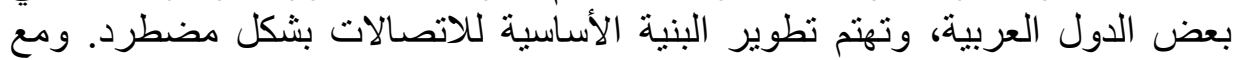

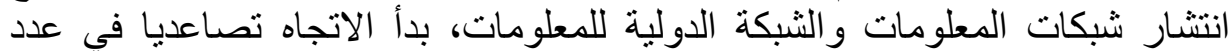

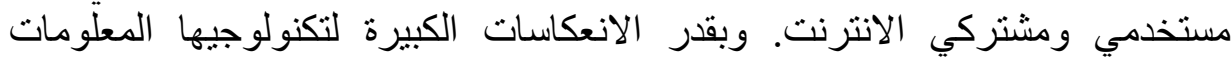




\section{د/بلال بوترعة - بوقروزاميية}

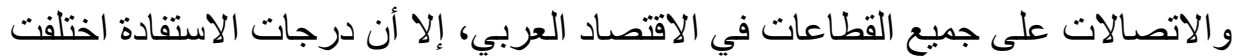

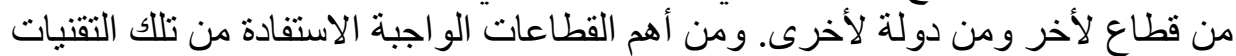

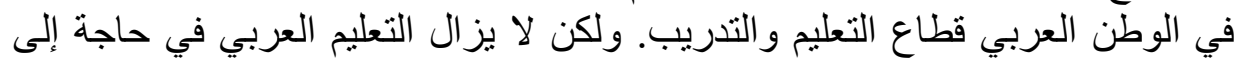

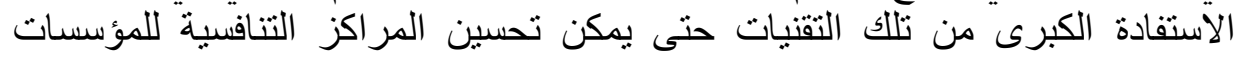

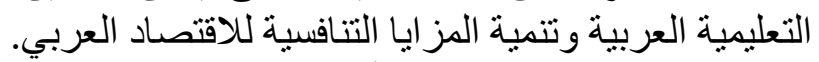

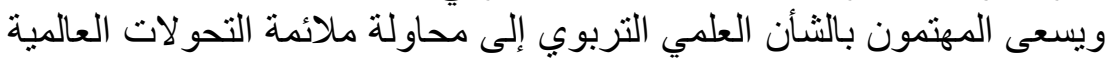

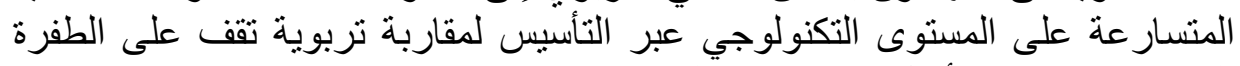

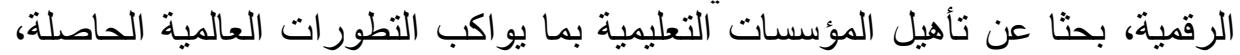

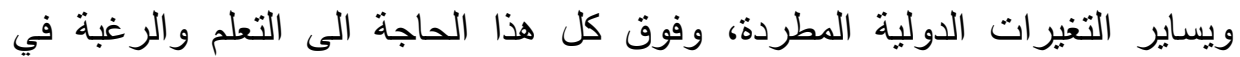

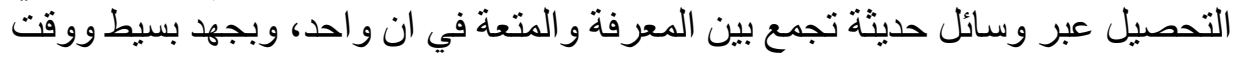

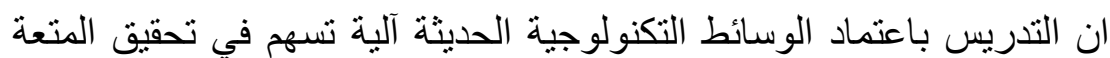

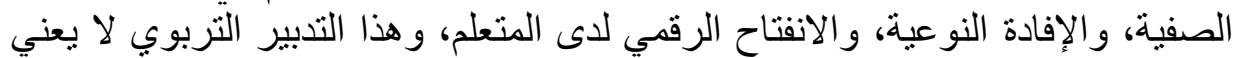

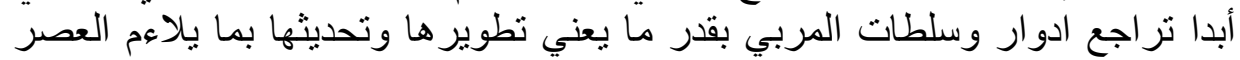

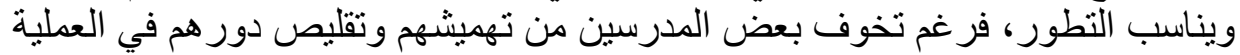

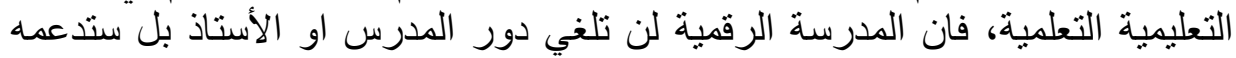

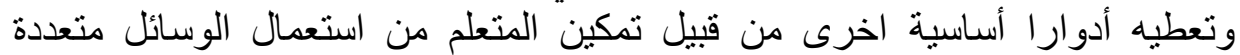

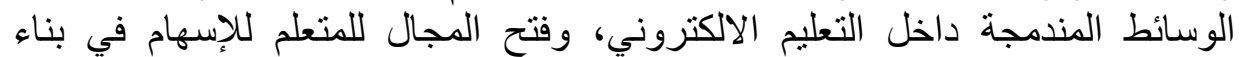

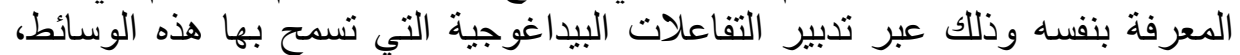

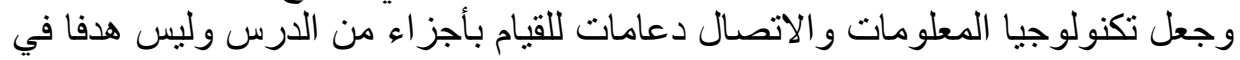
حد ذاتها.

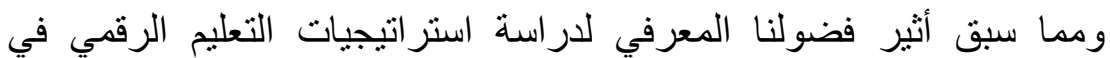

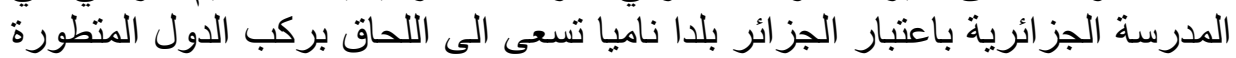

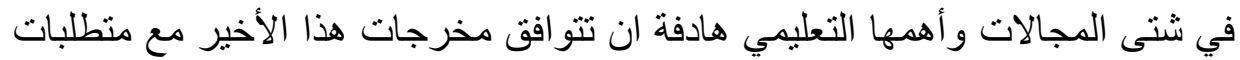
السوق العالمية. أولا- ماهية التعليم الرقمي: الرقية

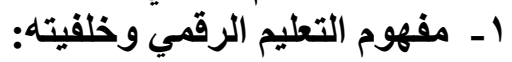

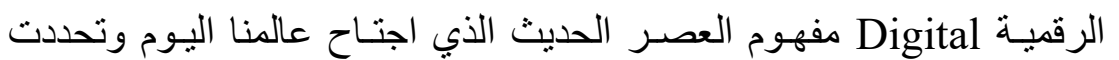
مفهومه:

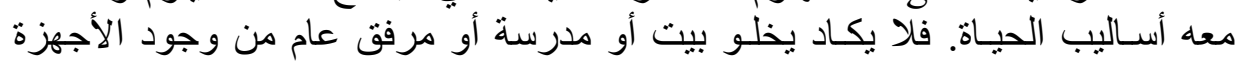

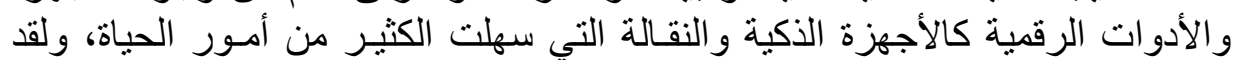

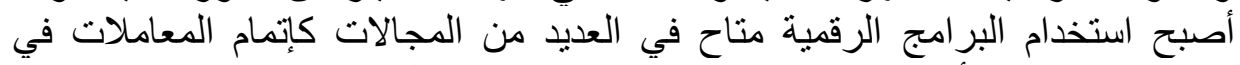

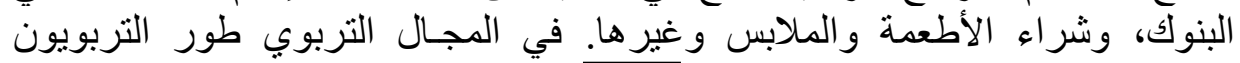


مفـاهيم كثيـرة لتتناسب مع طبيعة الحيـاة الجديدة التي فرضنتها التغيرات في مجال

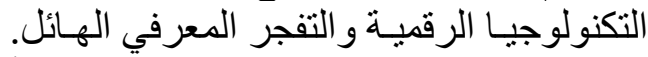

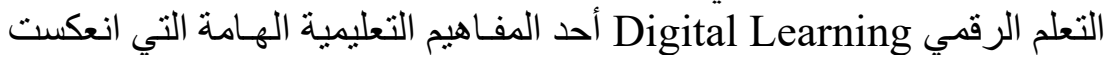

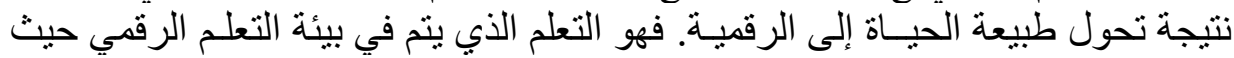

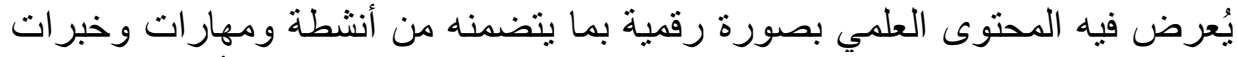
من خلال الوسائل و البرامج التكنولوجية الرقمية المتنوعة بغية تحقيق الأهداف التعليمية

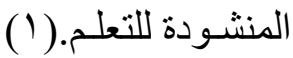

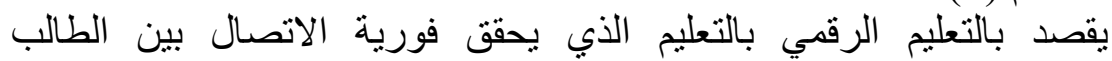

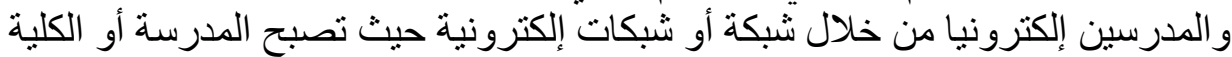

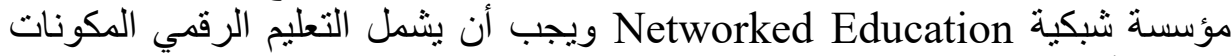

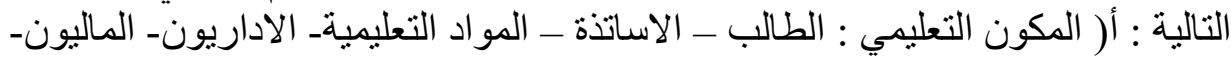

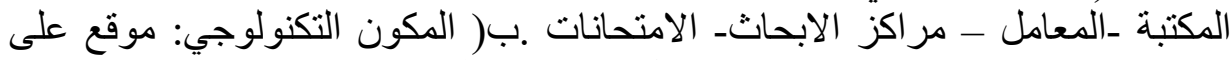

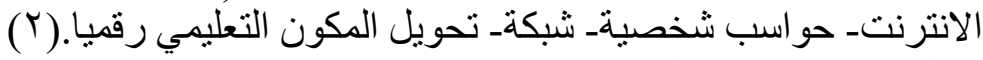
هنالك تعريفات كثيرة للتعلم الرقمي منها - :

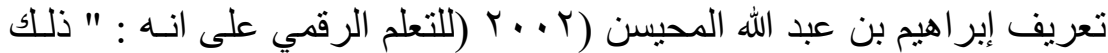

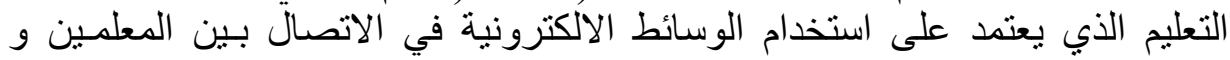

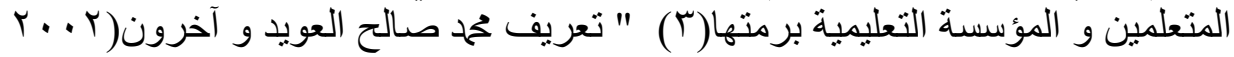

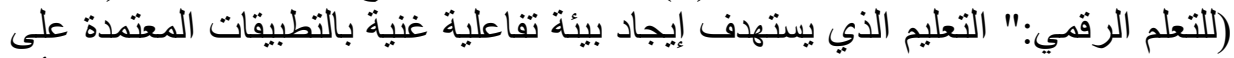

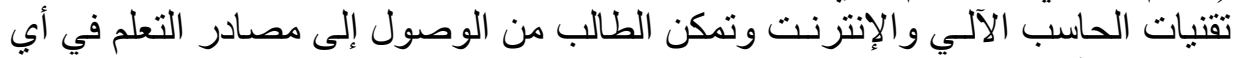

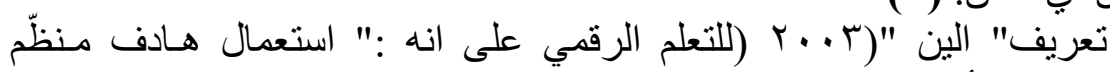

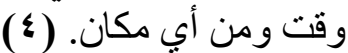

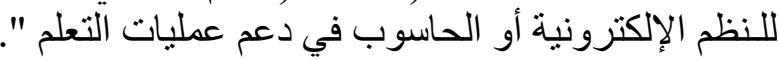

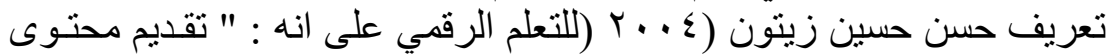

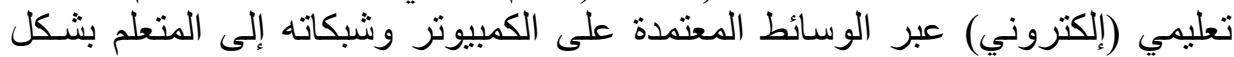

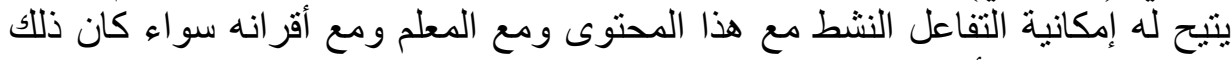

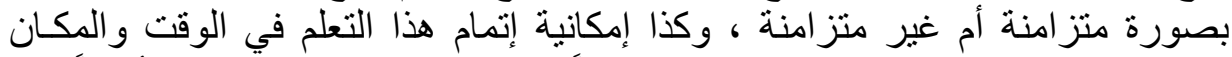

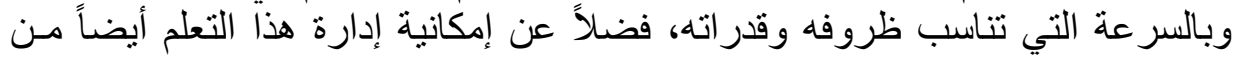

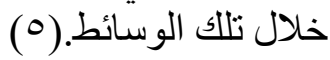
خلفيته: خلان

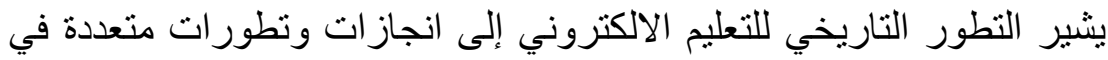

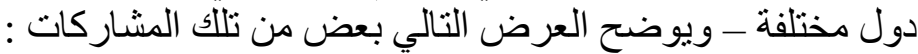

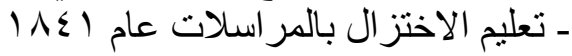

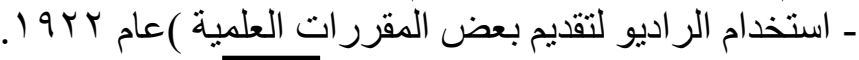




\section{د/بلال بوترعة - بوقروزاميية}

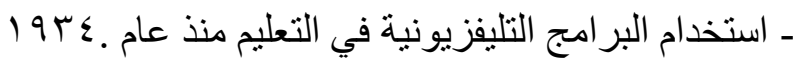

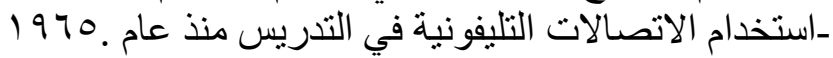

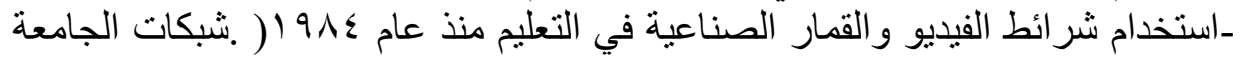

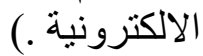

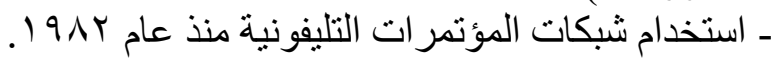

. The National University Teleconferencing Network (NUTN)

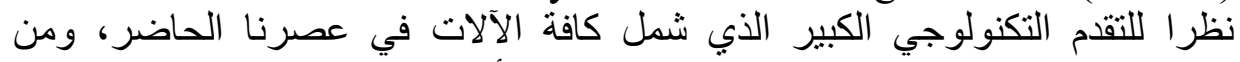

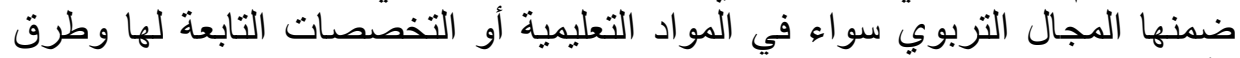

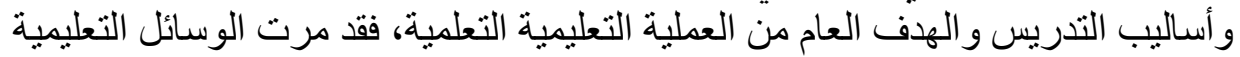

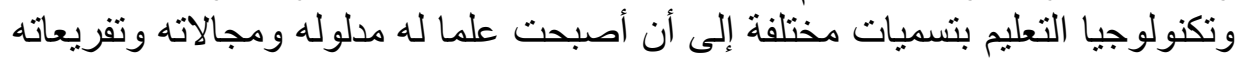

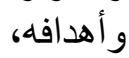

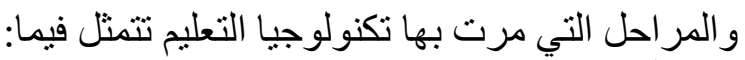

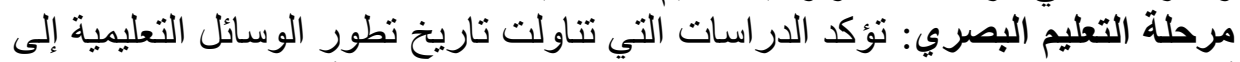

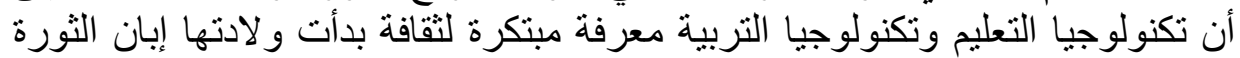

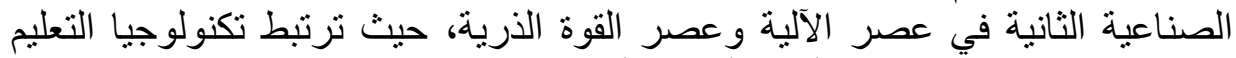

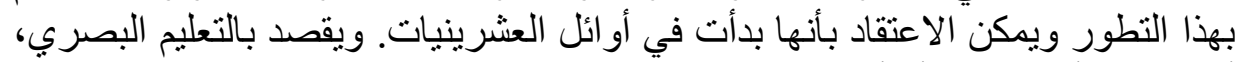

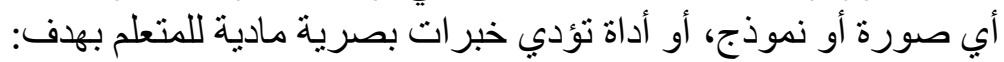

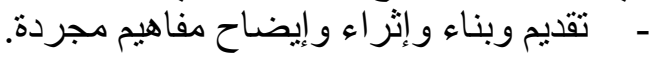

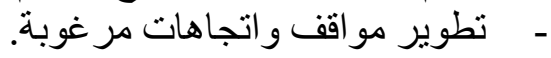

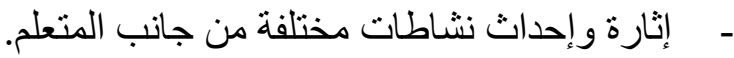

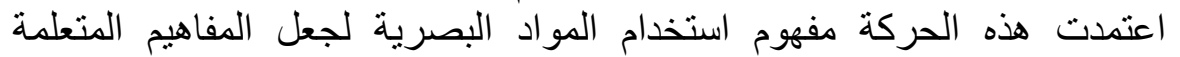

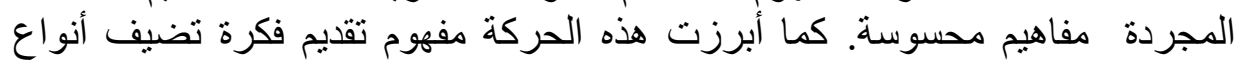

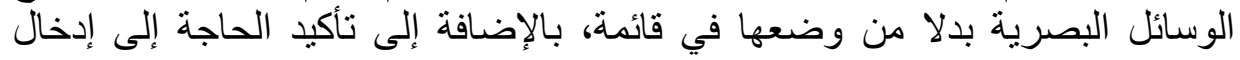

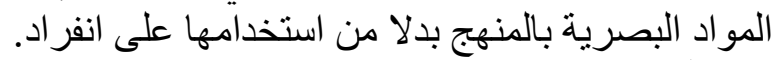

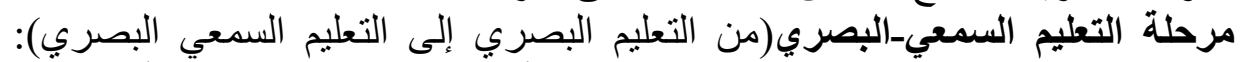

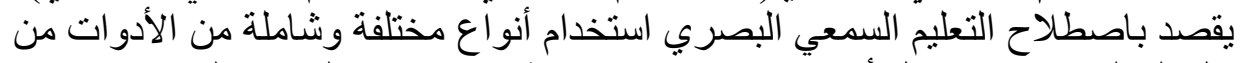

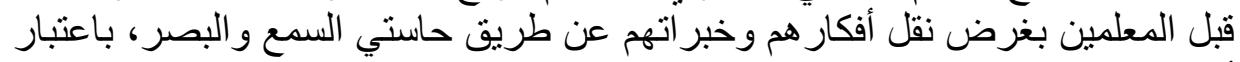

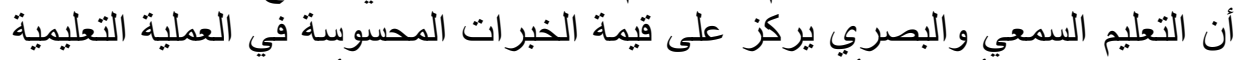

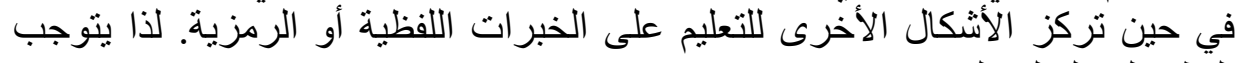
البصري كطريقة تعليم حديثة، لأن المواد السمعية البصرية تكون ذات قيمة فقط عند استخدامها كجز كُ متكامل ومتداخل من العملية التعليمية التعلمية. 


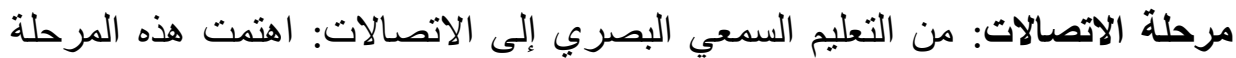

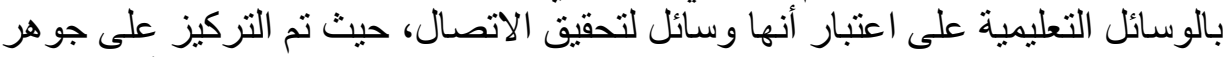

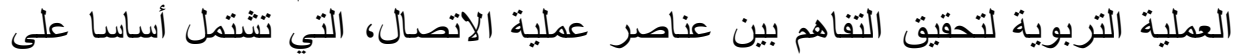

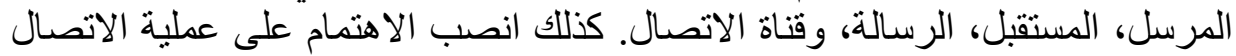

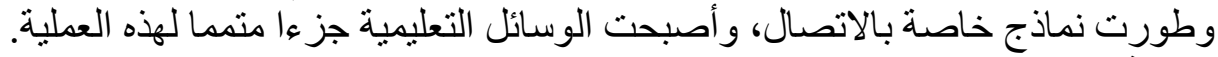

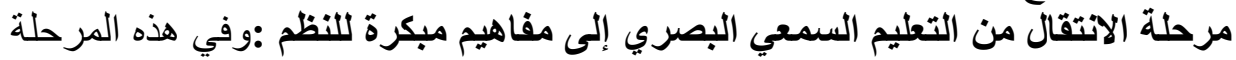

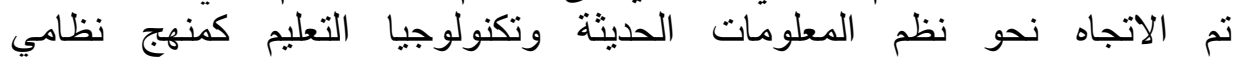

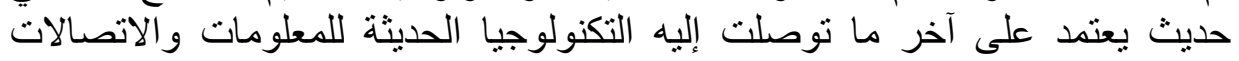
الفائقة

السر عة. ولقد ساعد مفهوم الأنظمة المبكرة لتكنولوجيا التعليم في تقديم عدة مفاهيم جديدة ومهمة نذكر منها: ـالقد أكدت على أن الوحدة الأساسية هي أنظمة تعليمية كاملة وليس مو اد تعليمية مستقلة.

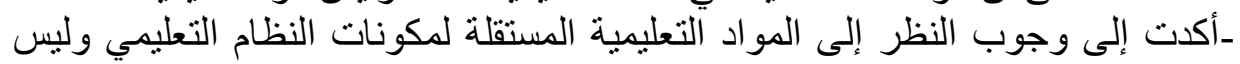

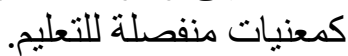

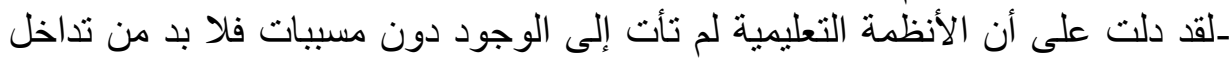
جل هذه المكونات بطريقة ما لتشكيل نظام معين.

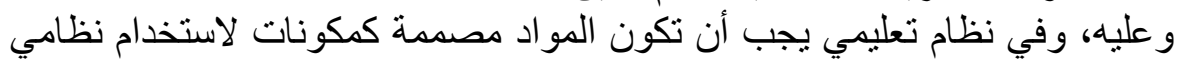

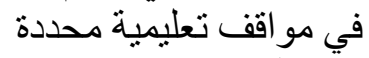
مرحلة الانتقال من الاتصالات السمعية البصرية إلى تركيب الاتصالات مع المفاهيم

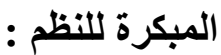
تؤكد هذه المرحلة أن الاتصالات السمعية البصرية هي فرع من النظرية التربوية

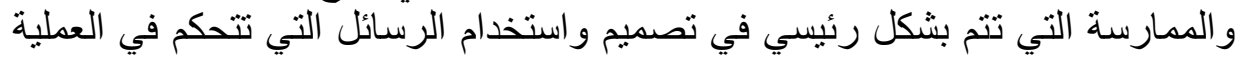

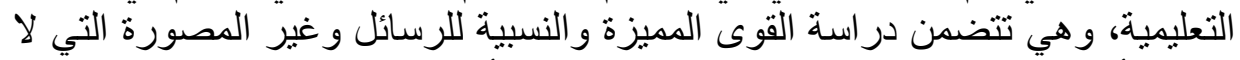

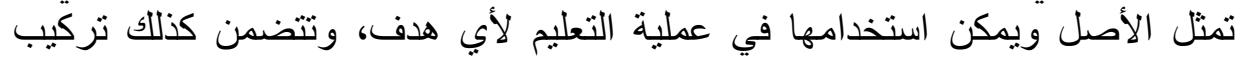

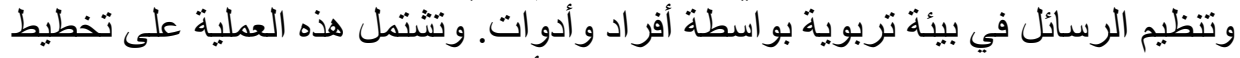

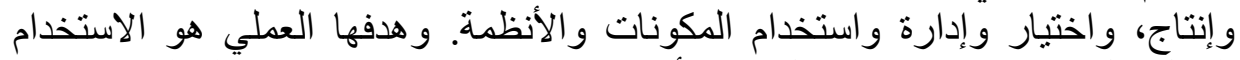

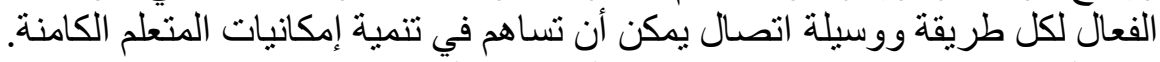

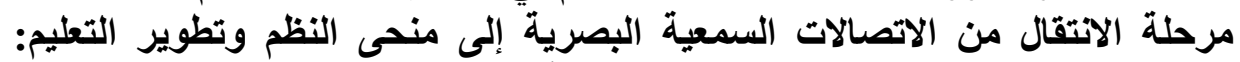

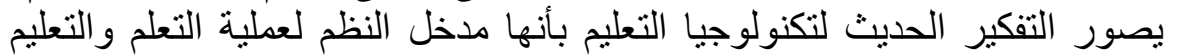

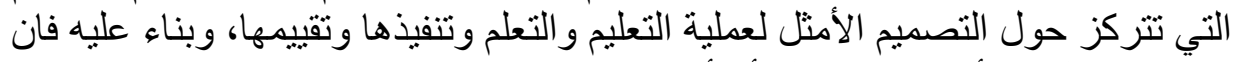

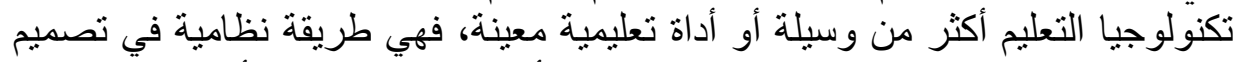

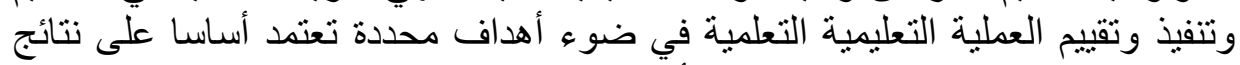
البحوث في التعلم البشري لتحقيق تعليم أكثر تفاعلية. 


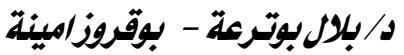

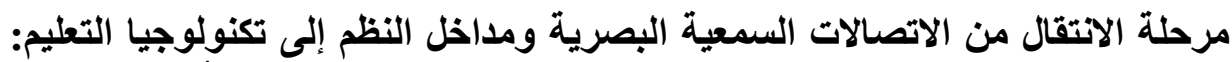

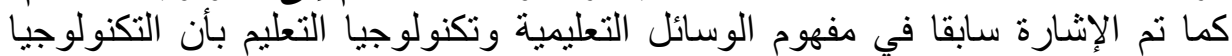

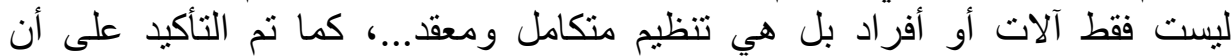

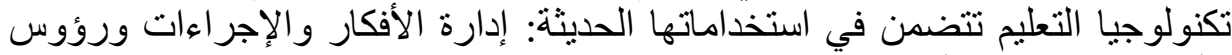
الأمو ال و الآلات و الأفر اد في العطلية التعليمية ما يلي: -

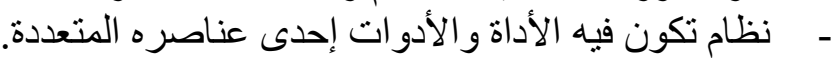

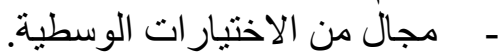

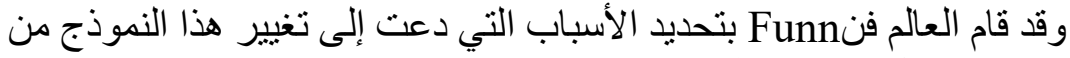

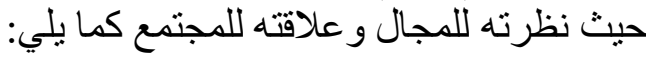

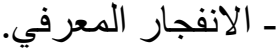

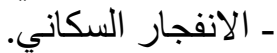

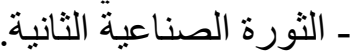
ـ ـ الثورة الديمقر اطية و العلمية والصناعية والثئية الثقافية.

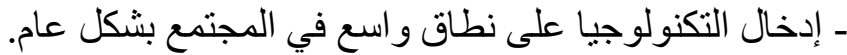

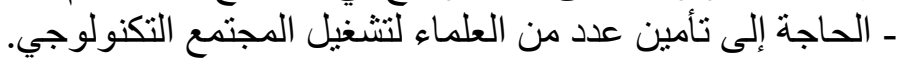

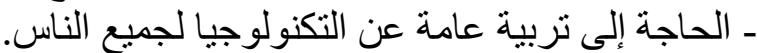

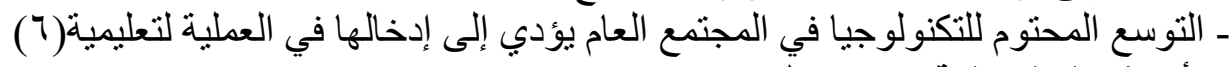

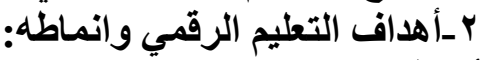

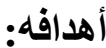
1- سد النقص في أعضاء هيئة التدريس و المتدربين المؤهلين في بعض الهجالات، آما

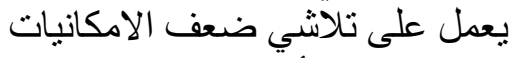

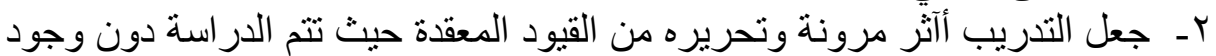

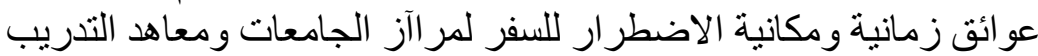

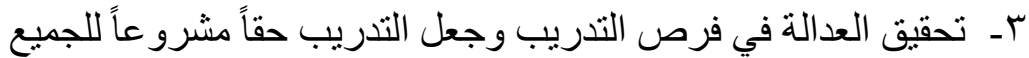

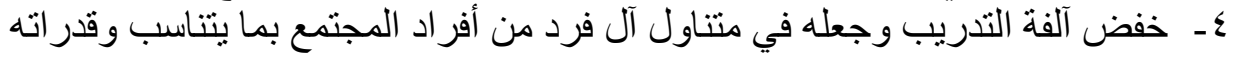

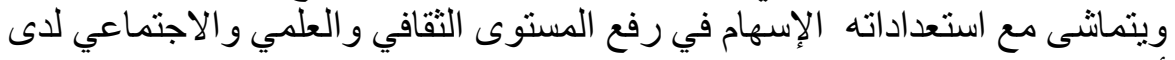

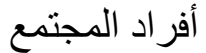
هـ ـ العمل على التندريب و التعليم المستمر

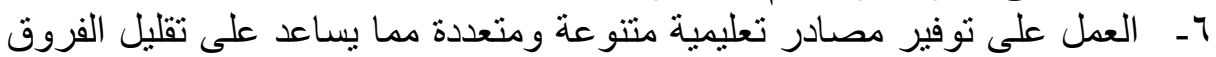

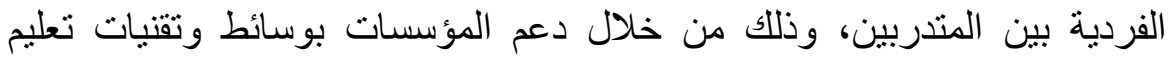

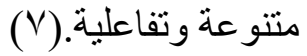




\section{أنماطه:

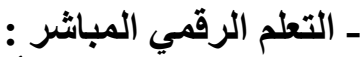

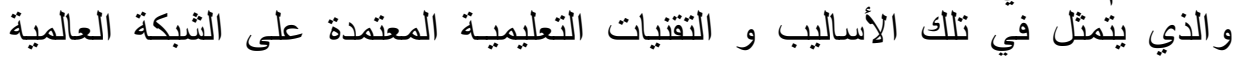

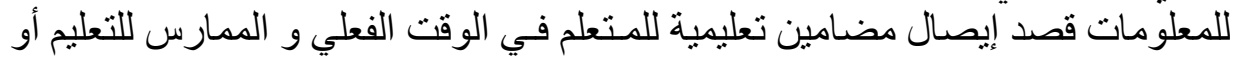

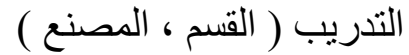

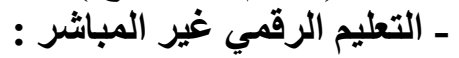

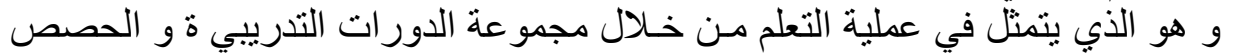

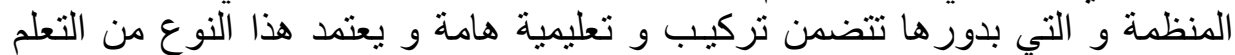

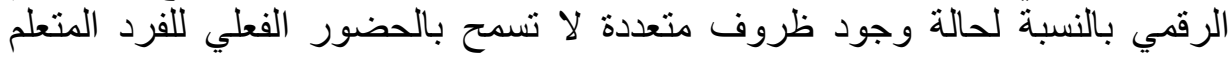

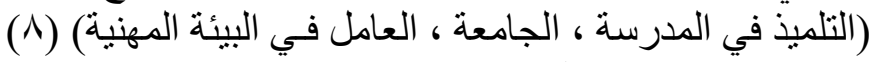
بـمميزات التعليم الرقي في ووسائلها:

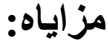

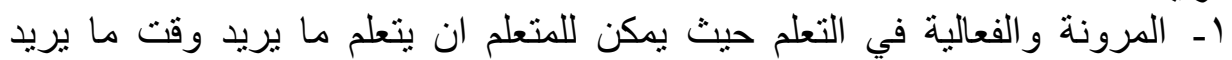

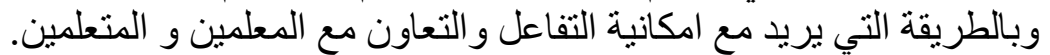

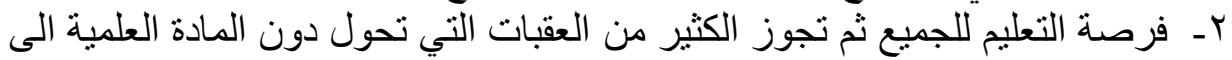
المناطق النائية و الدول البعيدة.

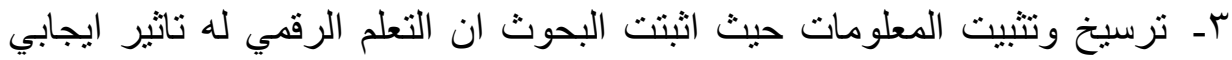

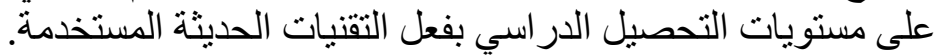

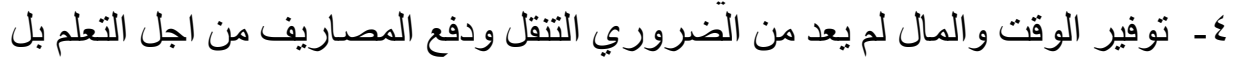

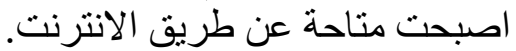

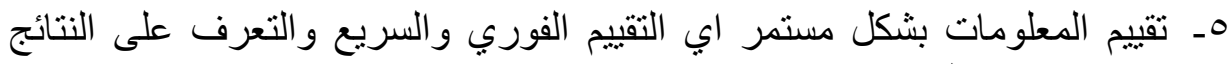
وتصحيح الاخطاء.

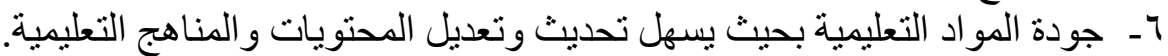

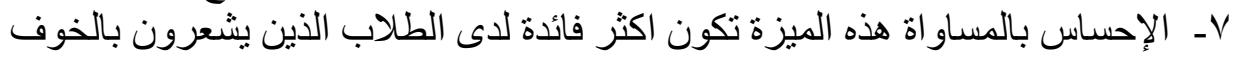

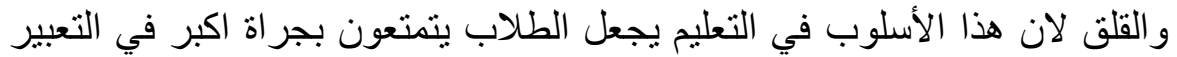

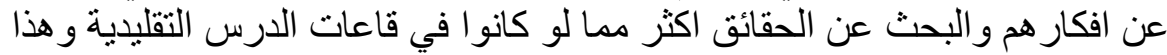

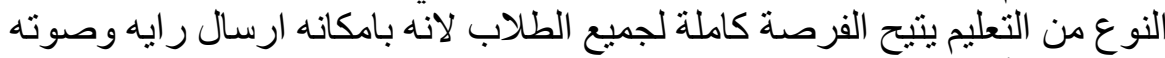

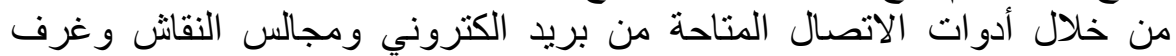
الحوار. - مان. 1ـ ـ ملائمة اساليب التعليم المختلفة التعليم الالكتروني يتيح للمتعلم ان يركز على الافكار

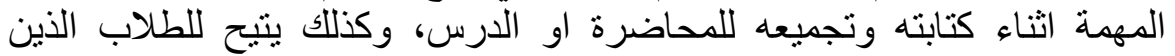

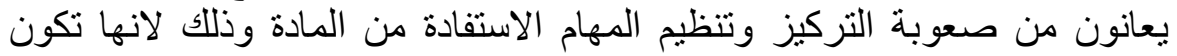

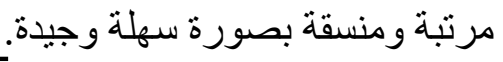




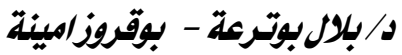

9- الاستمرارية في الوصول الى المناهج هذه الميزة تجعل الطالب في حالة استقرار

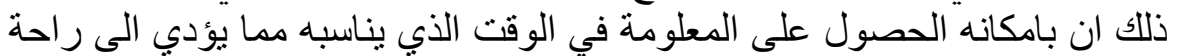

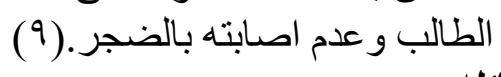

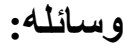

الاتصال المباثر : من خلال هذا الأسلوب يتم التخاطب في اللحظة نفسها بو اسطة:

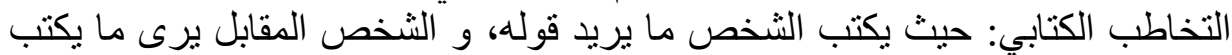

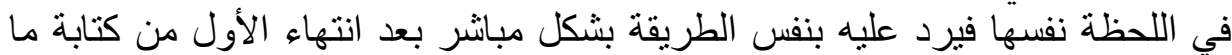

التخاطب الصوتي: حيث يتم التخاطب صوتيا في اللحظة نفسها عن طريق الانترنت.

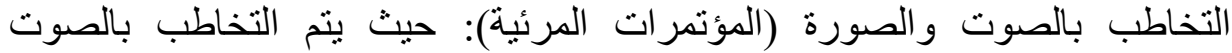

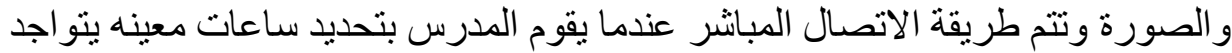

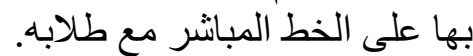
ثنانيا: استراتيجيات التعليم الرقمي: برى الكثير من التربويين و التكنولَوجيين أن التنافس العلمي هو أساس من أسس التعلم إذبا

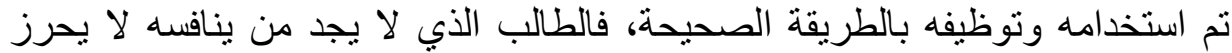

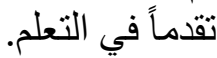

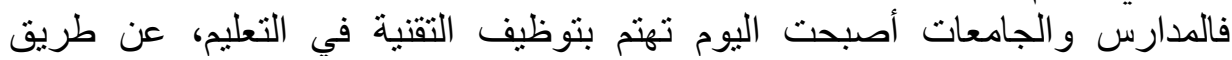

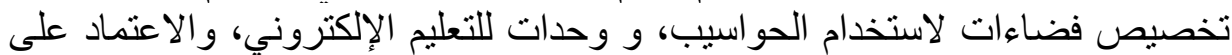
المقرر ات الإلكترونية في التعلم، و اعتماد استر اتيجيات حديثة مثل:

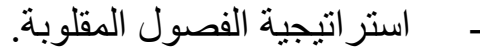
- - ماستر اتيجية المشاريع الإلكترونية. -

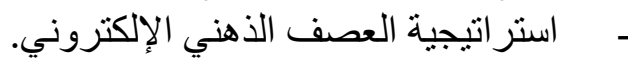
-

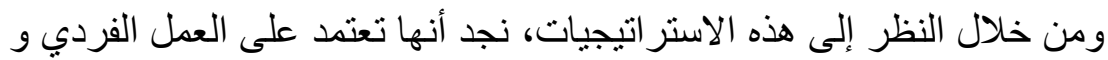

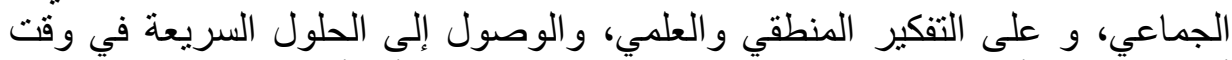

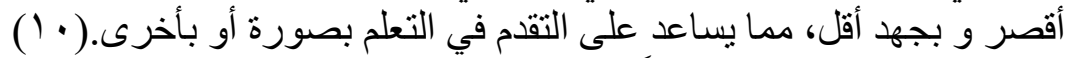

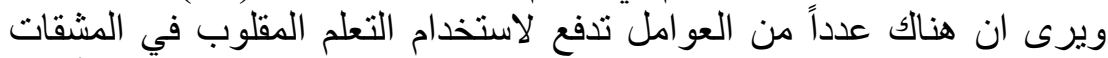

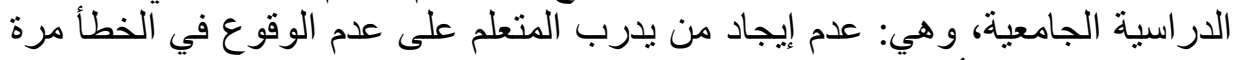

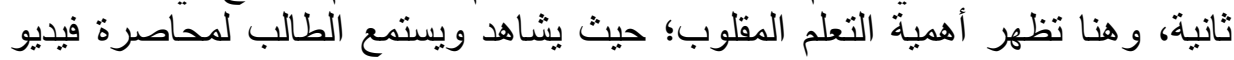
عبر الويب في البيت، ويؤدي بعس التعيينات الإلكترونية التابعة لها حتى يثل لمرحلة 
اتقان لمهارات المحاصرة إنها وسهل ذلك استخدام الطلاب للتكنولوجيا الحديثة

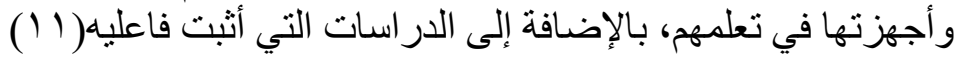

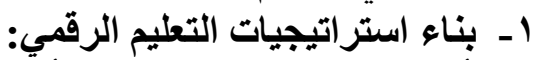

أكدنا في هذه الورقة الفنية أن التعليم الرقيمي يحتاج إلى إلى آلية لتحقيق الاتصال

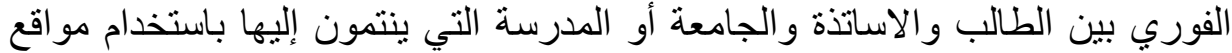

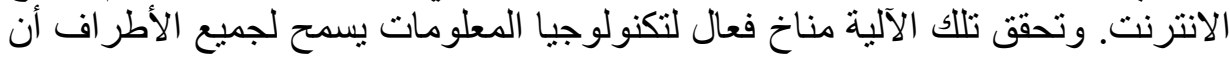

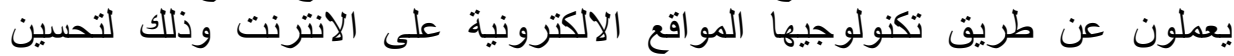

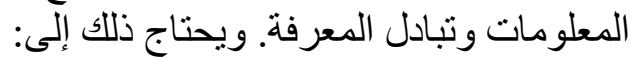

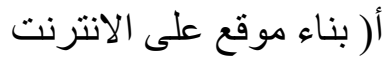

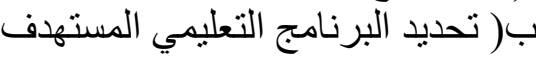

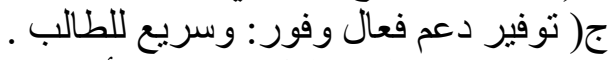

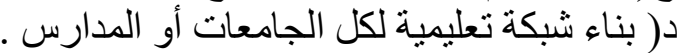

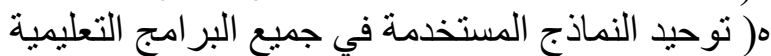

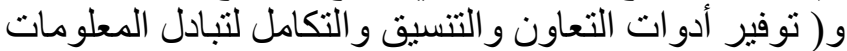

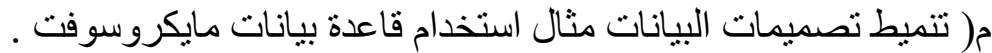

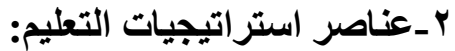

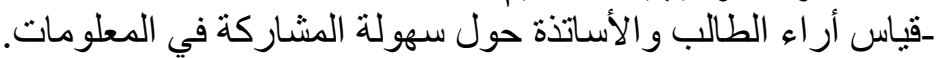

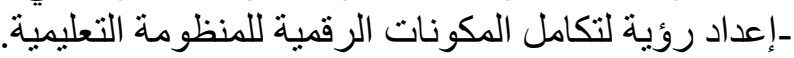

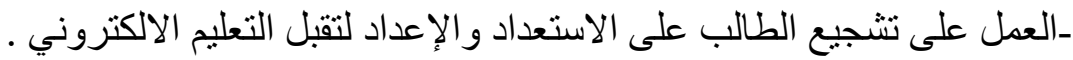

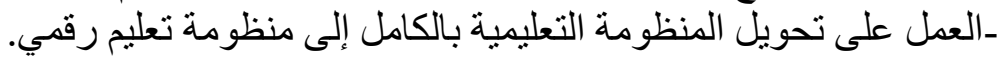

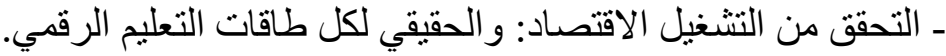

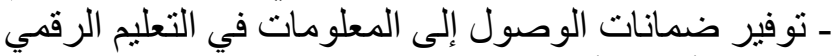

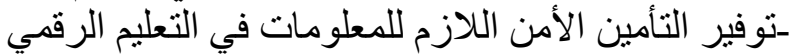

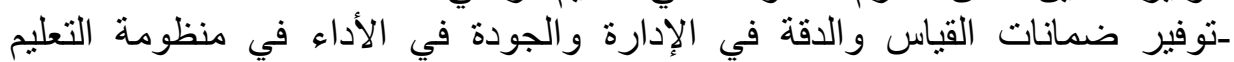

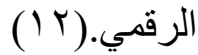

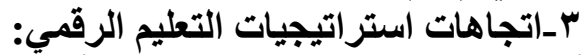
أ ) الانتظار حتى تظهر إستر اتيجية أحدثي التئي

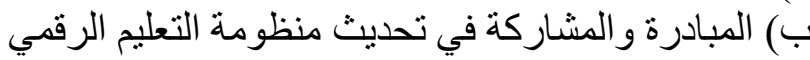

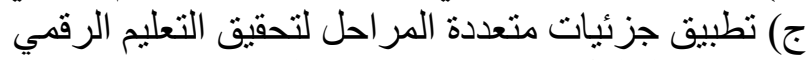

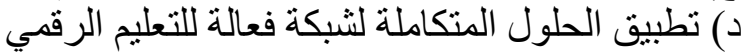

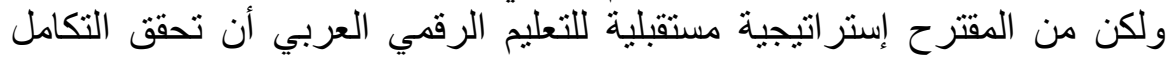

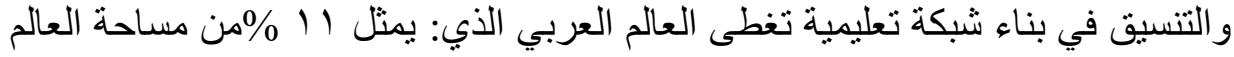




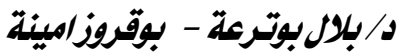

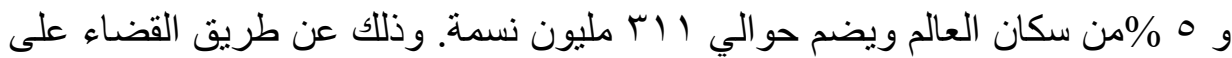
التهديدات البيئية ونقاط الضعف التبن التظيمي . ويتحقق التعليم الرقمي العربي من خلال تحديد:

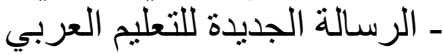

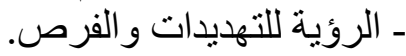

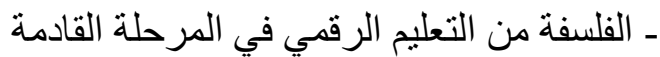

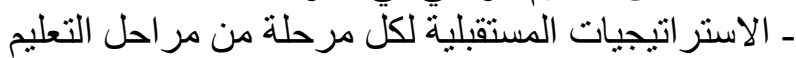

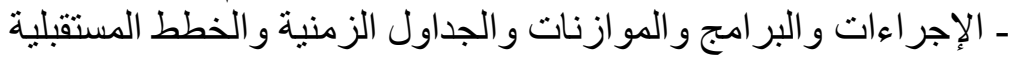

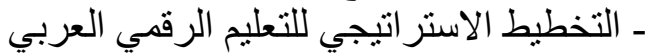

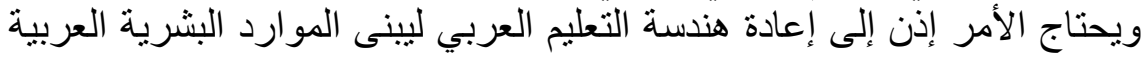

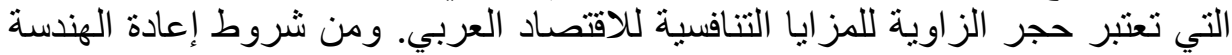

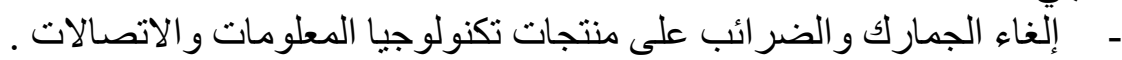

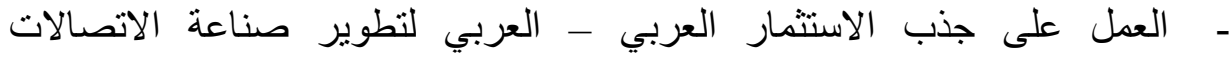

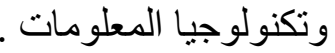

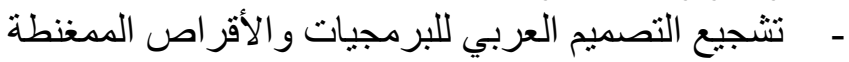
ـ التدريب المستمر للكؤادر العربية في مجال تكنولوجيا المعلومات والاتصالات بناء قاعدة بيانات لكل أنثطة تكنولوجيا المعلومات والاتصالات لقطاعات التعليم

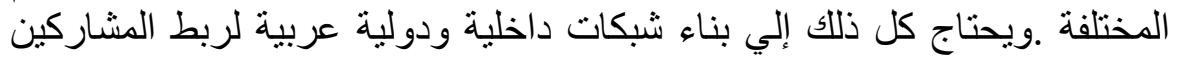
بالبر امج التعليمية والتدريبية التيختلفة. ثالثا: تحديات الرقمنة في المدرسة الجزائرية: الترائة

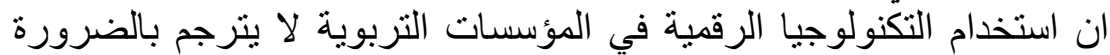

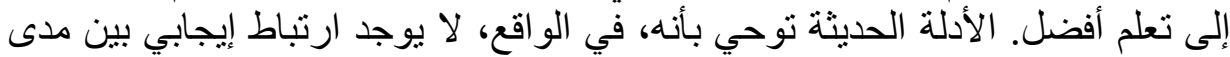

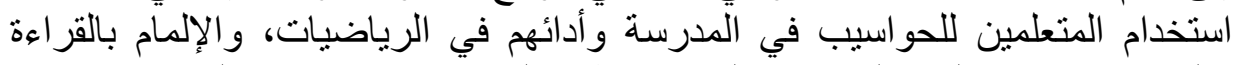

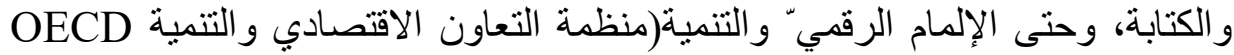

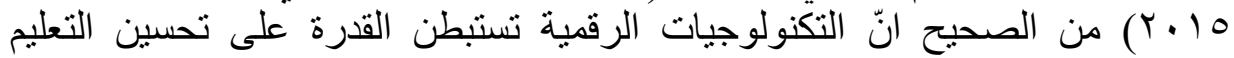

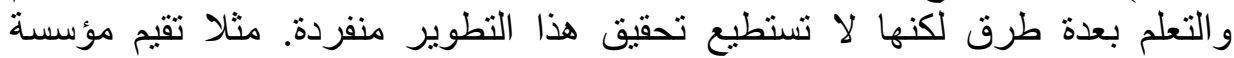

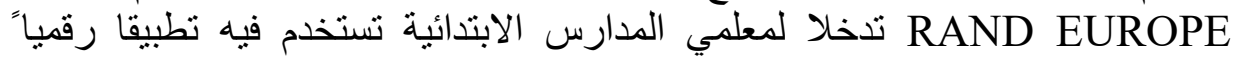

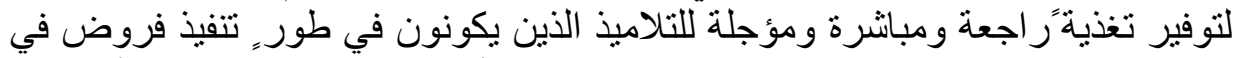

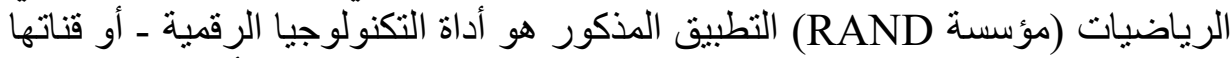
ـ التي يتمكن المعلمون بواسطتها من توفير التغذية الراجعة. لكن هذه الأداة ستكون فعالة التهات 
فقط في حال كانت التغذية الراجعة التي يوفر ها المعلمون عالية الجودة ان استخدام

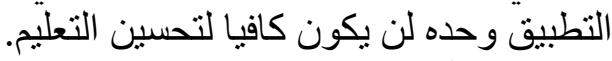

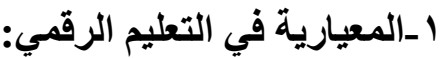

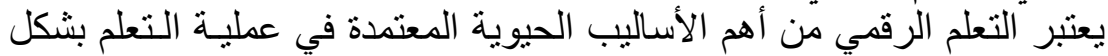

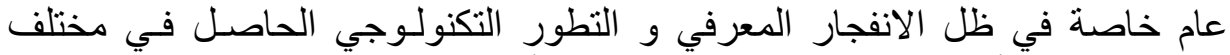

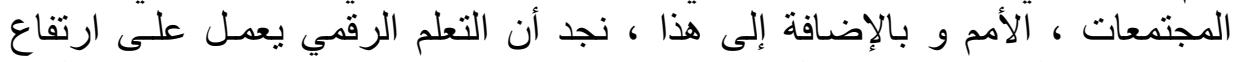

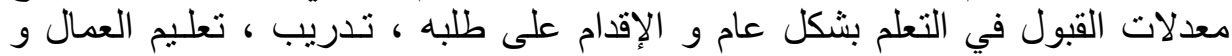

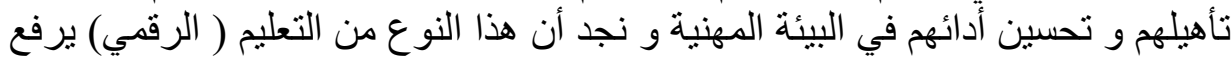

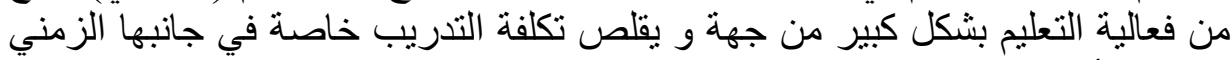

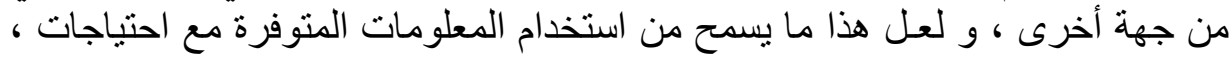

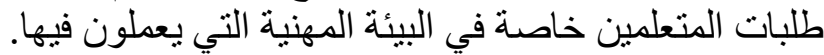

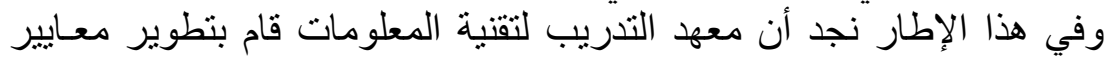

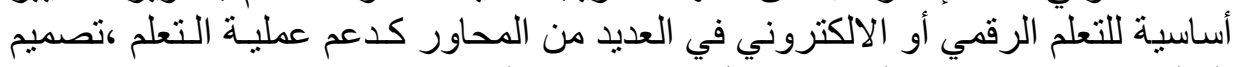

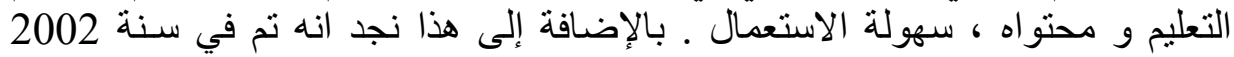

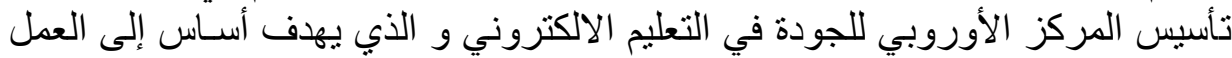

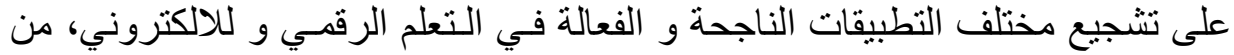

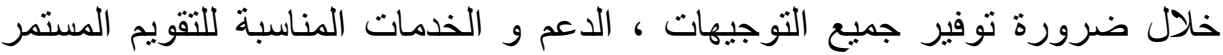

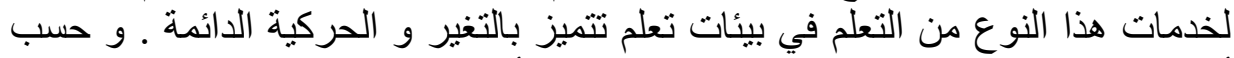

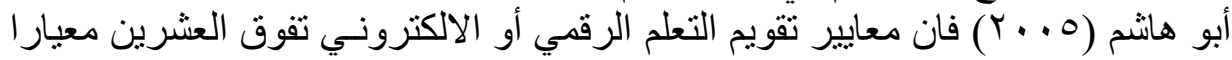

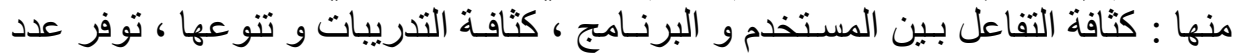

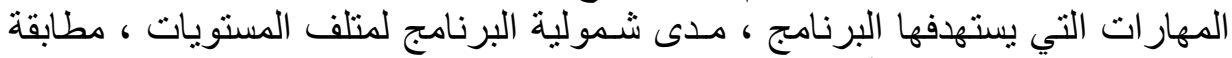

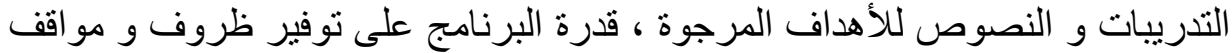
تعليمية و تدريبية تساعد المستخدم على التعلم )متعلم في البيئة المدرسية ، البرجية البيئة

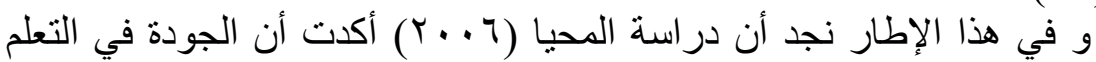
(المهنية).(T)

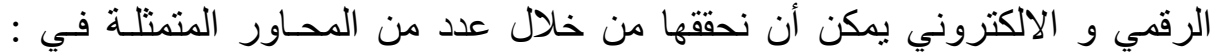

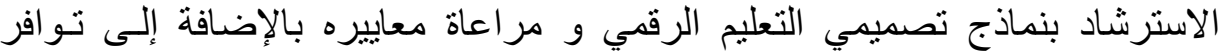

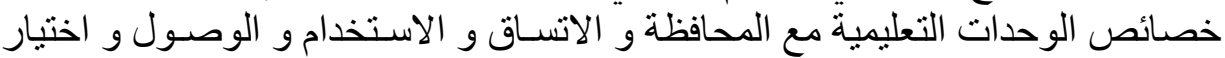

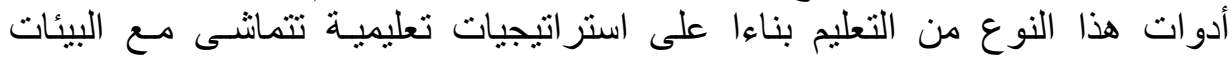
التعليمية الرقمية المختلفة.

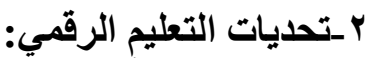

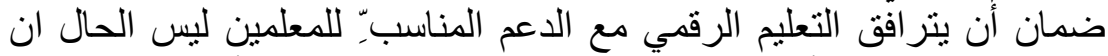

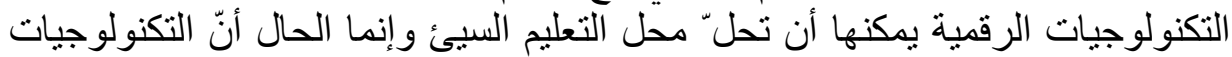




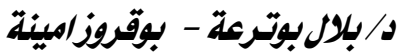

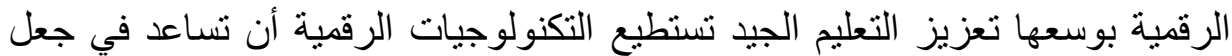

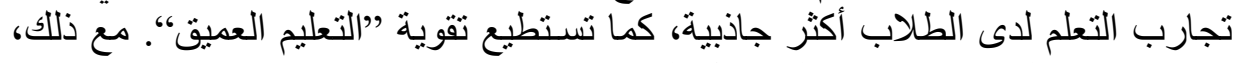

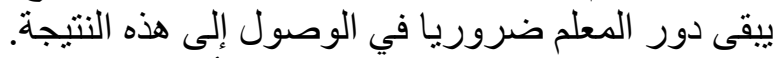

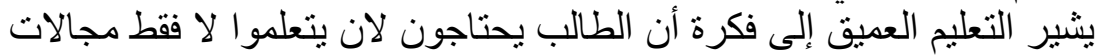

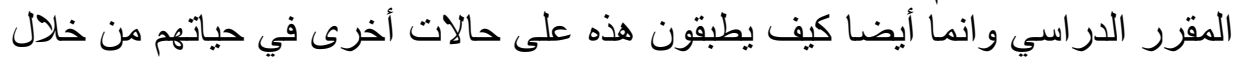

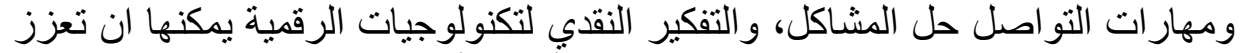

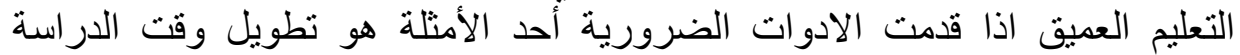

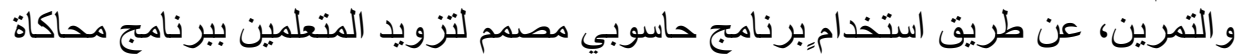

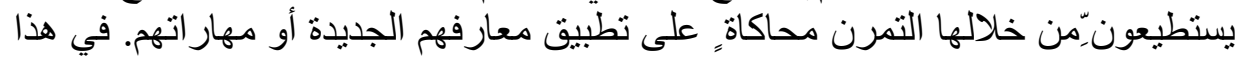

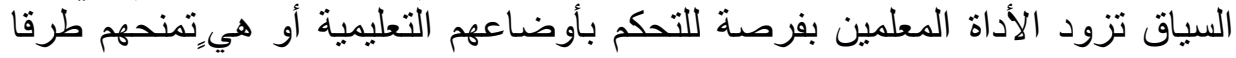

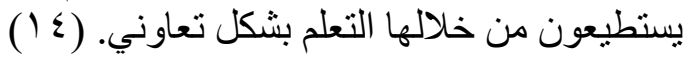

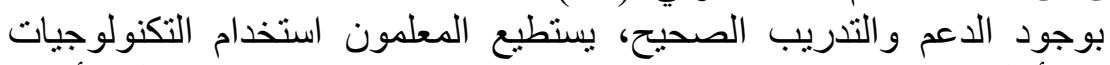

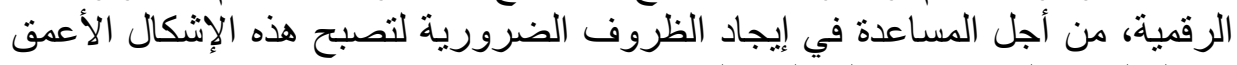

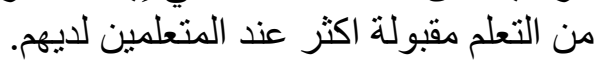

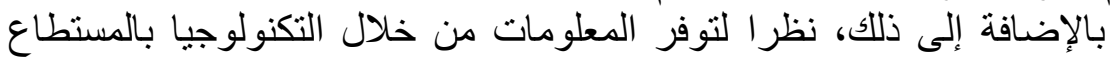

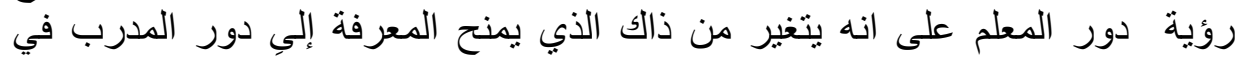
المستقبل، بدلا من ان يقوموا بتوفير المعلومات بينطيع المعلمون التركيز على تدريب لئي

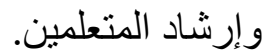

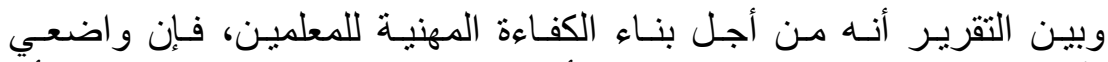

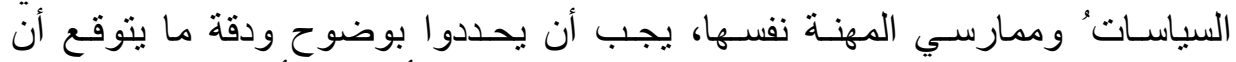

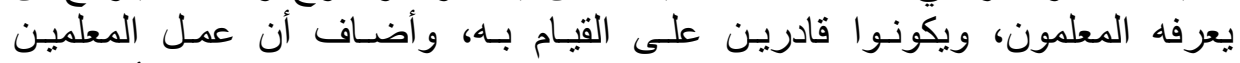

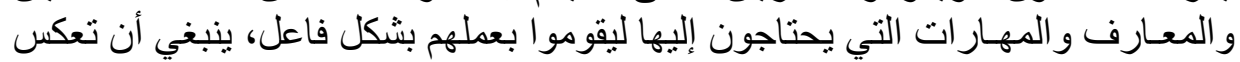

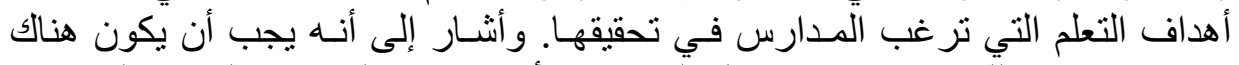

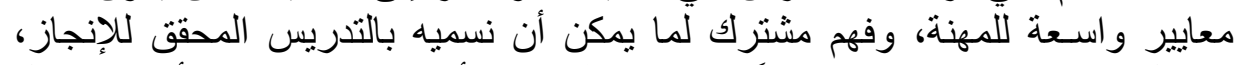

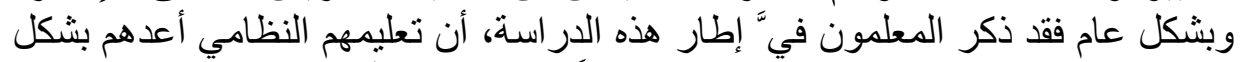

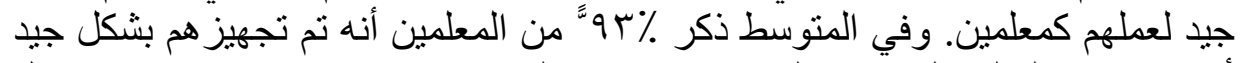

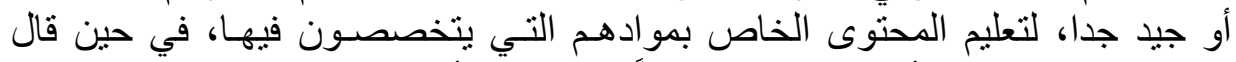

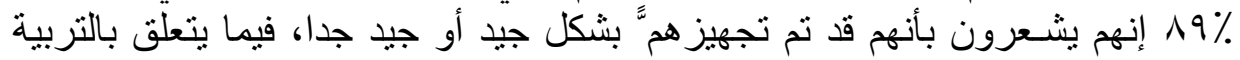

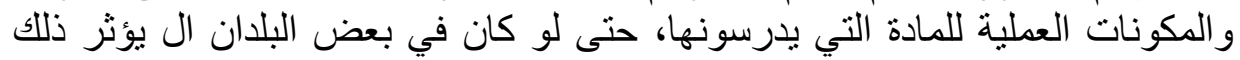

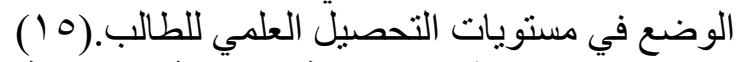
ب-التعليم الرقمي في المؤسسة التعليمية الجزائرية: 


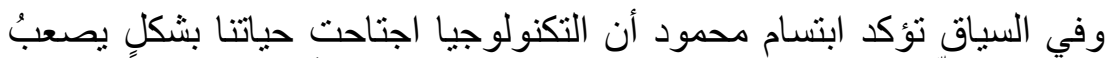

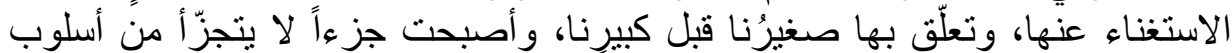
حياتنا.

فهي تُشهّل الكثير من الوظائف، وهناك العديد من التأثير ات الإيجابية المرتبطة

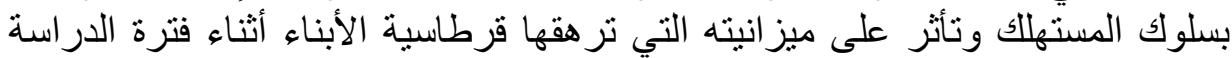

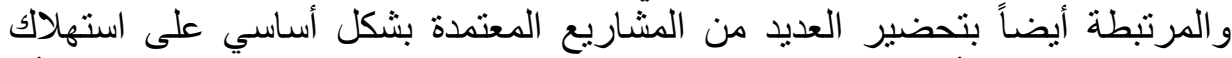

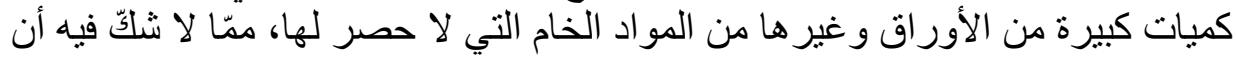

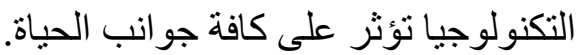

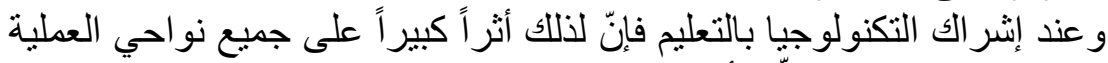

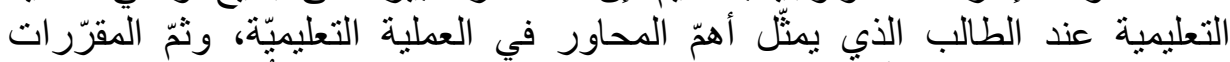

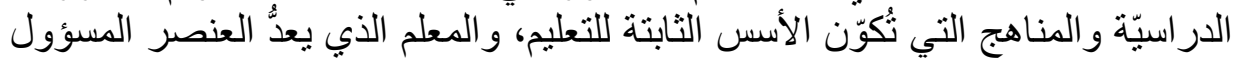

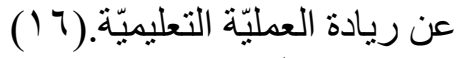

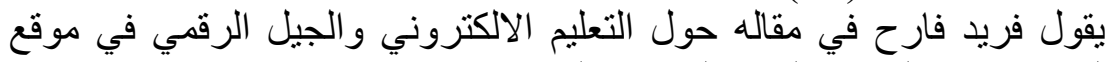

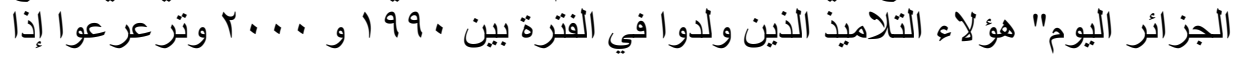

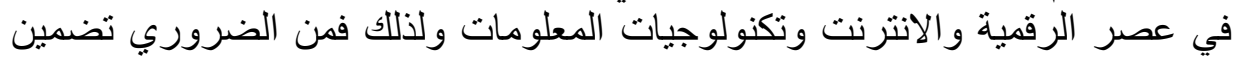

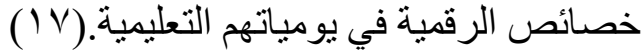

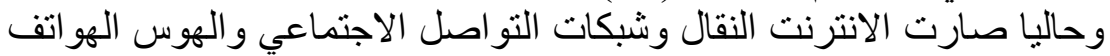

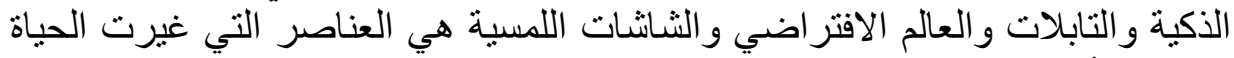

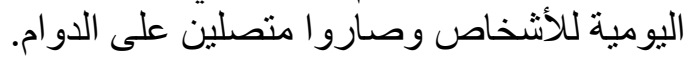

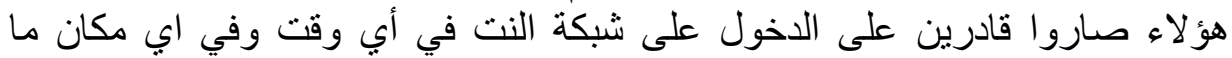

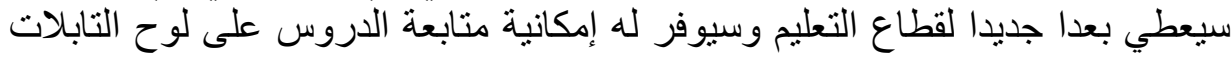
محليا او عبر نطبيقات نقالة.

وأيضا من اجل تحسين المستوى التعليمي لتلاميذ الجيل الرقمي الذين صلاروا

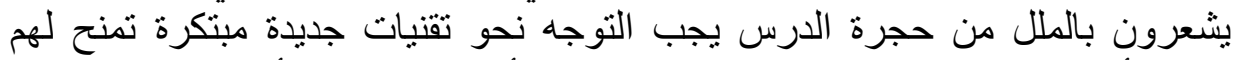

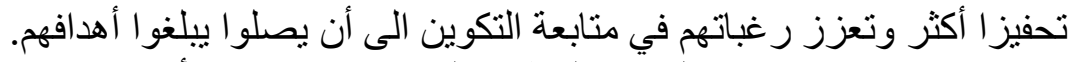

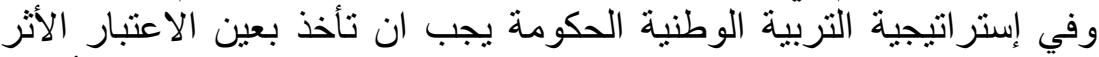

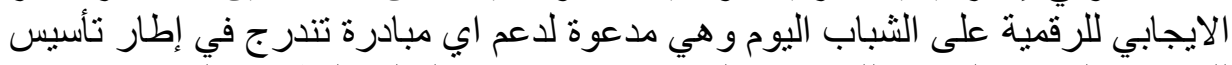

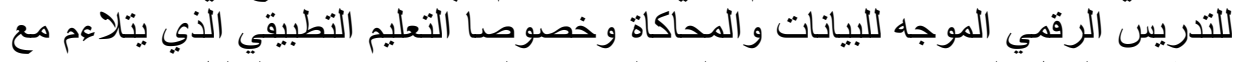

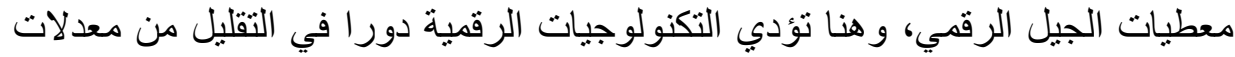

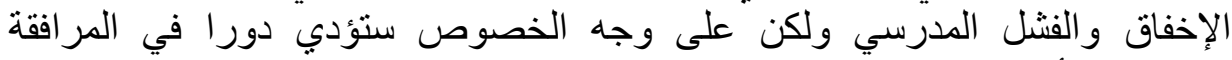
المدرسية للأشخاص من ذوي الاحتياجات الخاصة. 


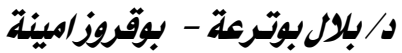

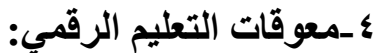

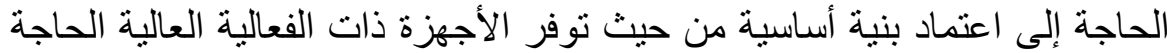

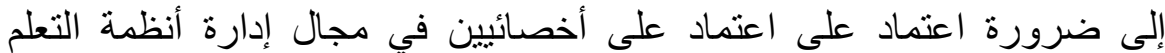

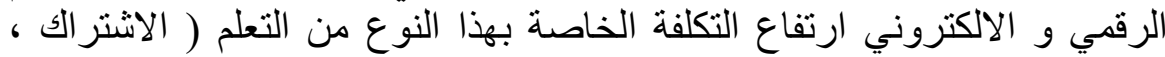

تصميمي البر امج و الاكترون

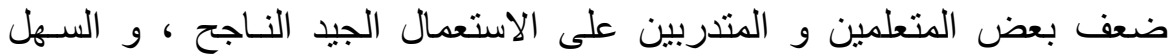

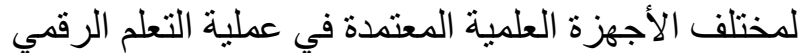

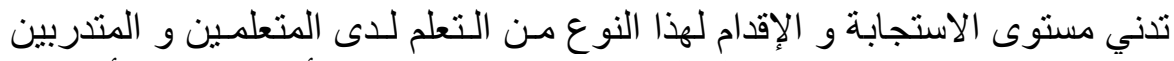

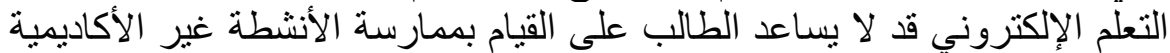

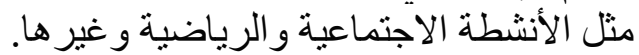
ارتفاع تكلفة التعلم الإلكتروني وخاعة الرباصة فئهة في المر احل الأولى الألى من تطبيقه، مثل تجهيز

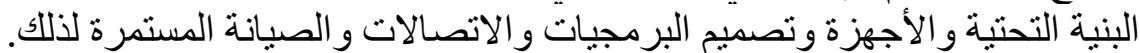

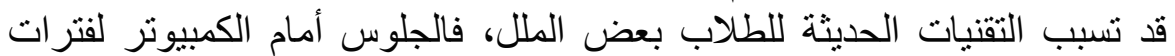

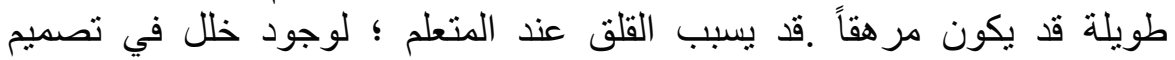

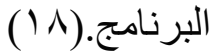

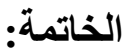

يتساءل المهتمون بالعملية التعليمية هل نحن في مرحلة سنشهد فيها ردة فعل

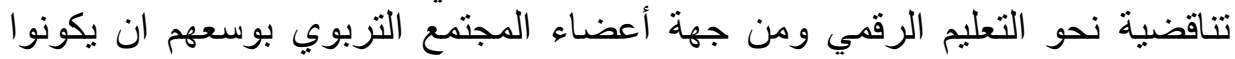

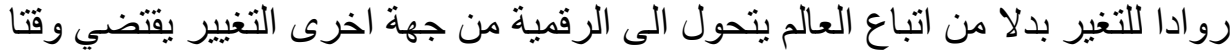

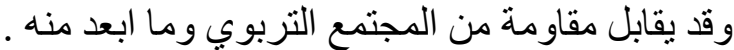

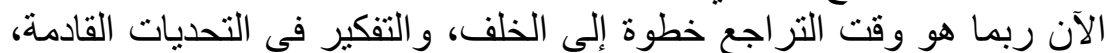

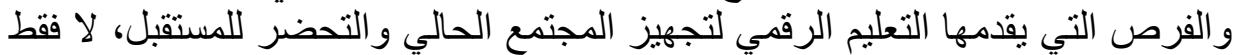

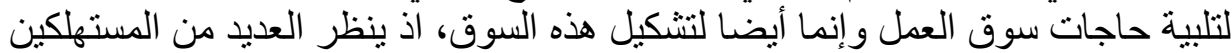

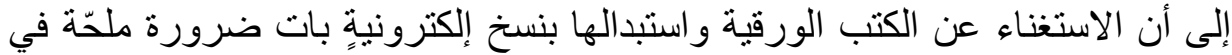

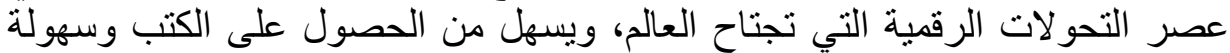

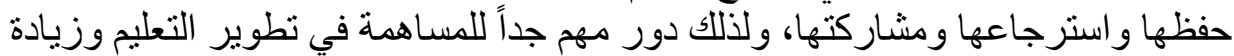

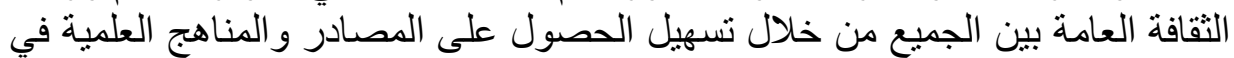

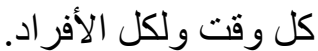

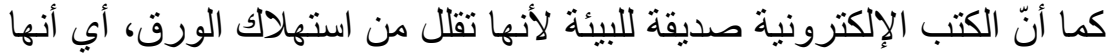

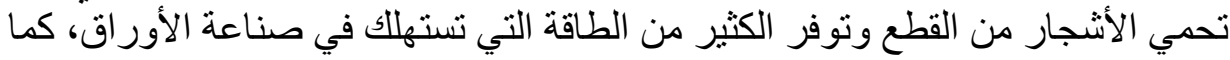
تقلل من كمية النفايات الورقية بتقليل استهلاكها. 


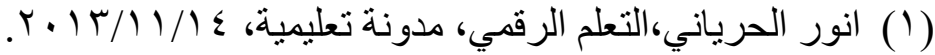

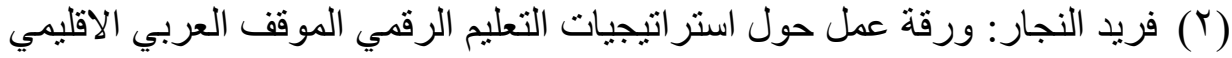

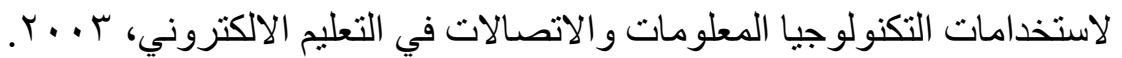

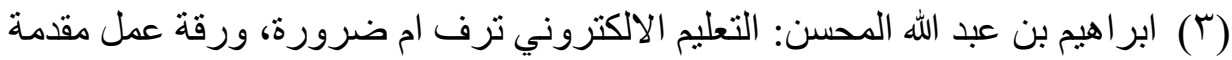

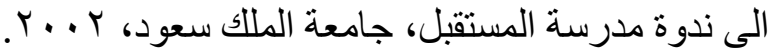

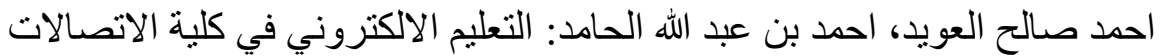

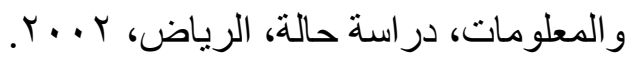

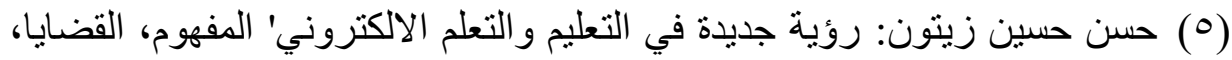

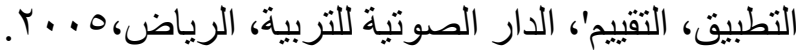

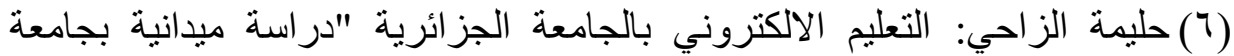

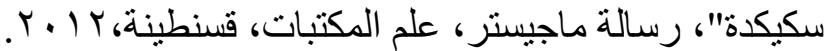

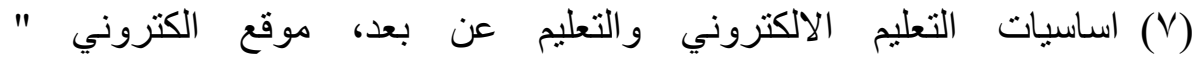

file://C:/Users/Chems-

6 $\quad$ "eddine/Downloads/cpit $\% 252$ b100\%252bch8\%20(1).pdf $r \cdot 11 / 1 \cdot / 1 \varepsilon$

(^) لونيس علي: دور التعليم الرقمي في تحسين الاداء لاى المعلم و المتعلم، مجلة العلوم

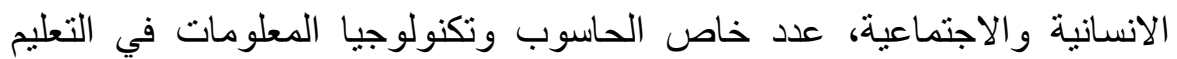

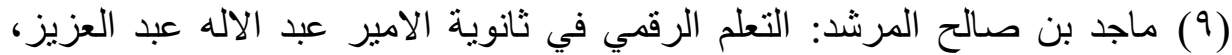

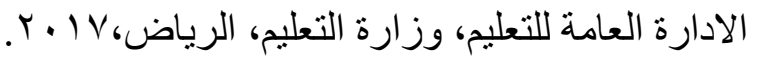

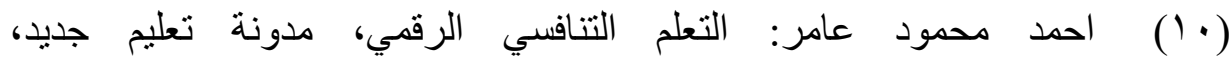
$.4 \cdot 1 \mathrm{~V} / \cdot 1 / 19$

سليمان احمد سليمان: فاعلية التعلم المقولب بالفيديو الرقمي، جامعة الأقصى،

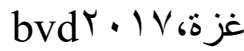

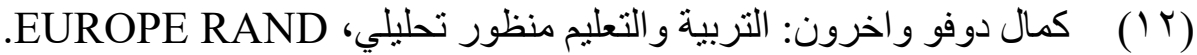

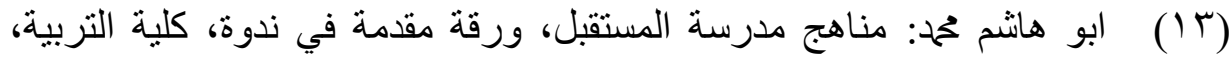

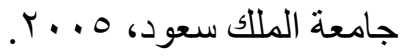




\section{د/بلال بوترعة - بوقروز/مينة}

( ع (1) كمال دوفو واخرون: التربية والتعليم منظور تحليلي، EUROPE RAND.

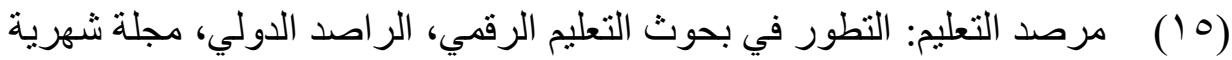

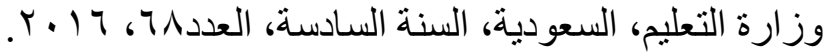

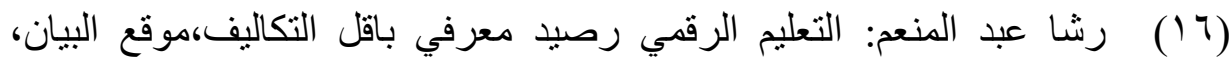
$r \cdot 11 / 1 \cdot / r q$

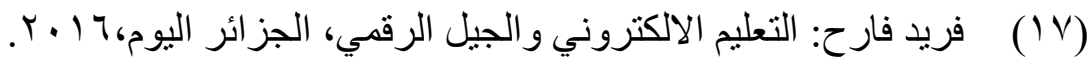

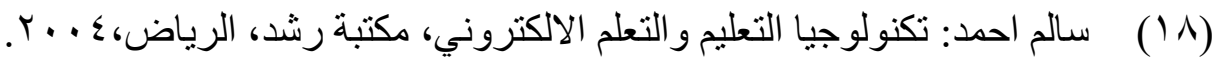

